The sexualityassemblages of young men: A new materialist analysis

\section{Pam Alldred}

Brunel University, UK

\section{Nick J Fox}

University of Sheffield, UK

\begin{abstract}
This article presents a new materialist exploration of young men and sexuality that shifts the focus away from bodies and individuals, toward the affective flow within assemblages of bodies, things, ideas and social institutions, and the sexual capacities this flow produces. Using data from two empirical studies, we explore the sexuality assemblages of teen boys and young men, and the micropolitics of these assemblages. We find that the sexuality produced in the bodies of young men is highly territorialised and aggregated by various materialities. However, we also reveal how young men resist these conventional sexualities.
\end{abstract}

\title{
Keywords
}

Assemblage, Deleuze and Guattari, new materialism, sexualities, young men

\section{Introduction}

Sociological studies of young men and sexuality draw on interactionist and poststructuralist perspectives, frequently inflected by feminist and/or queer theory (Pascoe, 2005: 331-332). ${ }^{1}$ The interactionist thread has revealed how people progressively learn a sexuality (Gagnon and Simon, 1973) via a repertoire of socially mediated attitudes, values, sexual scripts and behaviours that are transmitted to the bodies and minds of young men (and women), and how these are learnt, adopted, achieved or accomplished (Connell, 1987: 161; Frosh et al., 2002: 4; Schalet, 2011: 2). In Mac an Ghaill's (1994: 91) study of the socialisation of sexuality among teen

\section{Corresponding author:}

Professor Nick J Fox, University of Sheffield, 30 Regent St, Sheffield, SI 4DA, UK.

Email: n.j.fox@sheffield.ac.uk 
boys, an imperative to act like heterosexual men circumscribed both their everyday behaviour and their talk, which featured 'an obsession with ... penis size, uncontrollable urges and sexual potency' (1994: 91). Frosh et al. (2002: 50-52) found that boys were active, interpretive and critical subjects, who continually reinvented their sexual and gendered identities as they interacted with peers and others, while Bale (2011) noted that masturbation, accessing online pornography and interactions with a peer group actively influenced the development of teen boys' sexualities.

Post-structuralist concerns with institutional power relations and associated systems of thought/discourses provide further insights into young men and sexuality. Thus Schalet (2000: 79-80) found that differing parental discourses on young people and sexuality in the USA and the Netherlands articulated broader cultural understandings of human nature and social relationships. Pascoe's (2005) ethnography of a high school noted a 'fag discourse' that served to structure the social and power relations between boys (see also Alldred and David, 2007). Nayak and Kehily (2006: 465) argued that teen boys aimed performatively to reproduce an idealised 'perfect boy' manifesting a straight masculinity, while Moscheta et al. (2013) found that young men who traded sex sought either to subvert or conserve normative sexuality discourses.

Within both perspectives, 'hegemonic' masculinity (Connell, 1987) has been conceptualised as a subject-position (and related behaviours) based in 'compulsory heterosexuality, misogyny and homophobia' (Frosh et al., 2002: 76) that constitutes male power institutionally, experientially and discursively. It manifests within a culture that regards male violence and competitiveness as normal, appropriate and acceptable (Holland et al., 1998: 151; Kimmel, 2008: $217 \mathrm{ff}$.), denies attributes of dependency, nurturing and feeling associated with femininity (Lees, 1993: 306; see also Holland et al., 1998: 160), and ascribes homophobic epithets to boys who succeed academically (Epstein, 1998: 103). More recent formulations have developed this analysis, recognising the complex power relations that surround masculinity (Connell and Messerschmidt, 2005: 847-848), and the range of 'hybrid masculinities' that symbolically distance men from the hegemonic form by co-opting elements of marginalized/subordinated class, racial, sexual or gender identities, while sustaining sectional inequalities (Bridges and Pascoe, 2014: 254).

Arguably, such cultural models of young men and sexuality and a shift of attention toward 'masculinity' (understood as the concatenation of individual and collective behaviours, attitudes and subjectivities associated with 'being a man') have relegated sexuality, sexual desire and the physicality of sexual practices to the status of largely-unexamined backcloths to processes of socialisation and/or identity-construction (Beasley, 2014: 5). Desires, attractions and sexual behaviours are individualised, to be studied as attributes of specific human bodies, and constitutive of (individual) human subjects (Foucault, 1981: 157). In this article, we seek to overturn this 'anthropocentric' focus on bodies and identities. Beginning from a perspective of the materiality of sexualities, we will explore sexuality not as a bodily attribute, as the foundation of a subject's identity, or as the basis for individual 
sexual preferences, but as an assemblage of multiple bodies, things, ideas and social formations that cut across cultural and natural realms.

The emergence of 'new' materialisms in the social sciences (Coole and Frost, 2010; van der Tuin and Dolphijn, 2010) supplies the means to initiate this project. Focusing upon 'matter' and its social and physical production, we will apply a new materialist ontology of sexuality to explore empirical data on young male sexualities. We will shift the locus of sexuality from bodies and individuals toward the affective flow within assemblages of bodies, things, ideas and social institutions, and the sexual capacities this flow produces in bodies and collectivities (Fox and Alldred, 2013). We look at how a 'web of forces, intensities and encounters' (Braidotti, 2006: 41) between human and non-human elements produce specific, highly constrained manifestations of sexuality in young men, but also, importantly, continual challenges, fragmentations and resistances.

\section{New materialism, sexuality and the sexuality-assemblage}

'New' materialism has emerged over the past 20 years as an approach concerned fundamentally with the material workings of power, but focused firmly upon social production rather than social construction (Coole and Frost, 2010: 7; Taylor and Ivinson, 2013: 666). Unease over the 'textualisation' of bodies in post-structuralism led new materialist scholars including Barad (1996), Braidotti (2006), DeLanda (2006) and others to propose an ontology that asserts a central role for matter, and dissolves traditional mind/matter dualism in social theory (Braidotti, 2013: 4-5). Applied to empirical research, this perspective replaces the multiplicity of social theories that have been used to explain human culture (and human sexualities) with a simple focus upon the interactions between material forces. Significantly, it extends this materialist emphasis beyond traditional concerns with structural and 'macro' level social phenomena (van der Tuin and Dolphijn, 2010: 159), to consider also how desires, feelings, concepts and meanings have material effects and thus contribute to social production (Braidotti, 2000: 159; DeLanda, 2006: 5). This posthuman (Braidotti; 2006: 37) ontology shifts the focus for social inquiry from an approach predicated upon human agency (and its conceptual antithesis: 'social structure') toward examining the play of forces within relational networks or assemblages of animate and inanimate (DeLanda, 2006: 4; Mulcahy, 2012: 10; Youdell and Armstrong, 2011: 145).

A number of authors have applied new materialist perspectives to sexuality (Beckman, 2011; Braidotti, 2006; Fox and Alldred, 2013; Holmes et al., 2010; Lambevski, 2005; Probyn, 1995; Renold and Ringrose, 2011; Ringrose, 2011). Braidotti (2011: 148) described sexuality as a 'complex, multi-layered force that produces encounters, resonances and relations of all sorts', while elsewhere (Fox and Alldred, 2013: 769) we have suggested that the 'sexuality-assemblage' rather than the individual sexual body should be the focus of study, radically re-theorising sexuality as 'an impersonal affective flow within assemblages of bodies, things, ideas and social institutions, which produces sexual (and other) capacities in 
bodies'. Sexuality-assemblages bridge 'micro' and 'macro', private and public, intimacy and polity, and establish the capacities of individual bodies to do, feel and desire. They shape the eroticism, sexual codes, customs and conduct of a society's members, as well as the categories of sexuality such as 'hetero', 'homo' and 'bisexual' (Linstead and Pullen, 2006: 1299). In short, it is the sexuality-assemblage that is productive of all phenomena associated with the physical and social manifestations of sex and sexuality. We will now swiftly consider the conceptual framework required to explore this materialist perspective on sexualityassemblages.

First, the sexuality-assemblage asserts the fundamental relationality of all matter: bodies, things and social formations gain their apparent 'is-ness' only when in relation. Rather than taking the body or thing or the social organisation as a pre-existing unit of analysis, we look instead at the fluctuating assemblages that coalesce to produce both events and the apparent reality of the relations that they comprise. For example, a sexuality-assemblage accrues around an event such as an erotic kiss, which comprises not just two pairs of lips but also physiological processes, personal and cultural contexts, aspects of the setting, memories and experiences, sexual codes and norms of conduct, and potentially many other relations particular to that event.

Second, a sexuality-assemblage must be analysed not in terms of human or other agency, but by considering the assembled relations' ability to affect or be affected (Deleuze, 1988: 101); an assemblage's 'affect economy' (Clough, 2004: 15) can be understood as the forces shifting bodies and other relations 'from one mode to another, in terms of attention, arousal, interest, receptivity, stimulation, attentiveness, action, reaction, and inaction' (Clough, 2004). Within a sexuality-assemblage, human and non-human relations affect (and are affected by) each other to produce material effects, including sexual capacities and desires, sexual identities and the many 'discourses' on sexualities; these affects are qualitatively equivalent regardless of whether a relation is human or nonhuman. Importantly for the study of sexuality, desire may be understood as an affect in this ontology (rather than some essential quality of a body, no matter how culturally shaped), to the extent that it produces specific capacities to act or feel in a body or bodies, be it arousal, attraction, sexual activity, rejection or whatever.

This emphasis on affect economies and the changes they produce in relations and assemblages provides a dynamic focus for the study of sexuality and sexualityassemblages. Affects produce capacities to act, to feel or to desire, and studying a body's, a thing's or a social formation's capacities (and the limits and the possibilities for such capacities and capabilities) supplies a means to explore affect economies empirically. We may ask what a body can do within its relational sexuality-assemblage, what it cannot do, and what it can become. This opens to scrutiny both the affect economy within a sexuality-assemblage and its internal micropolitics that produces sexual desires, sexual responses, codes of sexual conduct, sexual identities and so forth. 
To study assemblage micropolitics, we apply two Deleuzo-Guattarian concepts: 'territorialisation' and 'aggregation'. We see territorialisation' (Deleuze and Guattari, 1988: 88-89) as an 'ecological' specification, not unrelated to the Francophone notion of 'terroir', a concept that describes how features in the immediate physical environment affect a vine's or a beehive's capacities to produce certain qualities in wine or honey. Similarly, affects deriving from relations in assemblages specify or 'localise' the capacities of a body or other relation. But territorialisation is not deterministic, because other affects 'de-territorialise' and 're-territorialise', re-shaping the possibilities and limits of what a body can do, continuously and unendingly. Sexual arousal, attraction, preferences and conduct can be understood as specific territorialisations produced by affects and desires in a sexuality-assemblage. So marketing aimed at children may territorialise ('sexualise') their bodies into adult sexual identities and choices (Bale, 2011), while a kiss may territorialise a body into sexual arousal. Yet that same kiss - say from a new lover, might open up a radically de-territorialising 'line of flight' (Deleuze and Guattari, 1988: 277), propelling a body into possibilities such as polyamory or a new life begun elsewhere.

We replace Deleuze and Guattari's (1984: 286-288) terminology of 'molar' and 'molecular' with, respectively, 'aggregative' and 'singular' affects (Fox and Alldred, 2014). Aggregating affects act similarly on multiple bodies, organising or categorising them to create converging identities or capacities. In the field of sexuality, ideas and concepts such as love, monogamy, chastity or sexual liberation; prejudices and biases; conceptual categories such as 'women', 'heterosexual', or 'perverted'; along with the discourses on human sexuality documented by Foucault (1981: 103-105) all aggregate bodies, producing (among other outputs) the pervasive social relations between bodies that traditionally sociology has summarised as 'patriarchy', 'heteronormativity' and 'hegemonic masculinity'. By contrast, other affects (for instance, a gift, smile or a caress from a lover) produce a singular outcome or capacity in just one body, with no significance beyond itself, and without aggregating consequences. Singular affects may be micropolitical drivers of de-territorialisation, enabling bodies to resist aggregating or constraining forces, and opening up new capacities to act, feel or desire.

Together, these micropolitical processes provide the starting point for the materialist exploration of young men and sexuality that follows. In this perspective, how sexuality manifests has little to do with personal preferences or dispositions, and everything to do with how bodies, things, ideas and social institutions assemble. Territorialising forces produce body comportments, identities and subjectivities, 'masculinity' and 'femininity'; and shape sexual desires, attractions, preferences and proclivities according to the particular mix of relations and affects in an assemblage. Sexual codes are culture-specific aggregating affects that establish the limits of what individual bodies can do, feel and desire in specific sociocultural settings, and produce the categories of sexual identity such as 'hetero', 'homo', polyamorous, queer and so forth (Barker, 2005; Linstead and Pullen, 2006: 1299). It follows that the sexualities thus produced 
in most cultures are conventional and prescriptive (Beckman, 2011: 9; Deleuze and Guattari, 1984: 294).

In the analysis of our research data that follows, we explore the micropolitics of young men and sexuality by disclosing the territorialisations and aggregations produced by flows of affect and desire in sexuality-assemblages. These flows cut across micro and macro levels, linking human and non-human (physical, social and abstract relations) to produce the (sexual) capacities of young men, the territorialisations that limit what their bodies can do sexually, and the de-territorialisations that enable them to resist.

\section{Methodology and methods}

This materialist agenda for the study of sexuality requires a posthuman methodology that firmly shifts the focus away from bodies and individuals toward relationality and assemblages, to affective flows in place of human agency, toward capacities to act, feel and desire rather than bodily attributes, and to a micropolitics of territorialisation and aggregation in place of fixity and social structure (Deleuze and Guattari, 1988: 257). To this end, a range of qualitative and quantitative collection approaches might be applied to a topic, generating a breadth of data, while remaining aware of the differential biases of different methods and designs (Fox and Alldred, 2014). Analysis of data must step away from efforts to reveal the 'authenticity' of respondents' accounts, disclosing instead 'the thick and affective materiality' of the world, culture and people's lives (Renold and Ivinson, 2014), and the territorialising and de-territorialising micropolitics within assemblages that link matter and meaning, and cut across 'micro' and 'macro' levels.

The data we present here is drawn from two studies, the first a multi-methods study of sex and relationship education (SRE) teaching in UK secondary schools conducted by the first author and her colleague (Alldred and David, 2007), which included individual and group interviews with teenage boys in school and alternative educational settings; the other a secondary analysis of a dataset of 31 interviews with male students, employed and unemployed young men living in London, undertaken as part of a study of masculinity. ${ }^{2}$ These disparate data - with their differing research designs and different subject-groups, offer a broader picture of the affective economies in the sexuality-assemblages of young men than might a single source: ethnographic and focus group data provide a rich seam of assemblage micropolitics, while interviews produce data on the relations and affects that variously link mind and matter.

Our analysis began by trawling the two datasets to mine the relations in these sexuality-assemblages, the affects that link them and the capacities these affective flows produce. This provided the basis upon which to focus our attention upon the micropolitics of the assemblages. Using the two dimensions of territorialisation/deterritorialisation and aggregative/singular outlined earlier, our objective was to map flows of desire and power (Ringrose, 2011) between human and non-human 
relations, and identify flux and fluidity (Masny and Waterhouse, 2011: 293) in the sexuality-assemblages of young men.

\section{The sexuality of young men assembled}

\section{Relations and affects}

The ethnographic observation of teen boys' sex and relationship education (SRE) classes (Alldred and David, 2007) revealed a sexuality-assemblage that also comprised peers, girls, siblings, teachers, condoms, second-hand cars, the school's SRE curriculum, and the school environment as affective relations. Within this affect economy, boys were affected by reported sexual behaviour within their peer group, but also by how SRE was taught and the interactions this entailed. The study found resistance to classroom values and relationship discussions, which the boys felt were none of the school's business, and also to expectations that they should discuss emotional issues with teachers or parents (preferring 'mates', a family member such as an older brother, or an outside facilitator). While teen boys in school in general supported SRE, for those excluded and in alternative educational provision, the SRE curriculum seemed irrelevant: for one teenage boy in this group, SRE could be reduced to a simple message about bodies, condoms and medical risks:

Sex is safe as long as you use a condom, you're safe. That's all that you need to know.

For this latter group, the embodied pleasure of sexuality was the dominant relation in the mix, providing a resource to resist both the tedium of the classroom and to reject the values and educational discourses that had produced them as academic failures and outcasts from school. Even the interviews conducted by the first author with this group of boys were treated as further opportunities to assert 'adult' (hetero)sexualities through sexual banter and horseplay, subverting a research agenda that they equated with a hegemonic educational regime.

The second dataset provides insights into sexuality-assemblages when young men were at university, at work or unemployed. The 31 young men interviewed were generally sexually active, ranging from occasional sexual encounters, reports of frequent casual relationships with partners met in social venues, through to steady relationships, and for one respondent, marriage. Three (Yusuf, Azim and Stephen) chose celibacy for religious reasons, but only one interview reported any same-sex activity: a drunken invitation that respondent Ross said he had declined. Close readings of interviews provided further insights into the relations and affects in their sexuality-assemblages. So for example, 20-year-old student 'Andrew' said:

I don't treat women very well, I suppose. My mum always gets on my back for this, but I don't - I mean I cheat on them, and I deceive them, which is wrong, and I know it's wrong, but I think I'm kind of insecure in myself in that respect. Which is ... I don't know why, but I just am. 
This extract supplied evidence of relations (women, mum), a flow of affect that linked them (Andrew's cheating and deceit, his Mum's disapproval) and capacities (cheating, insecurity), while analysis of the entire transcript indicated a sexualityassemblage that encompassed current and past girlfriends, male mates, alcohol, bars and clubs, physical attributes and a range of idiosyncratic elements including a chronic illness, sport, body size and Andrew's academic studies. The affective flow in this assemblage (for example, the physiological effects of alcohol; the emotions associated with the health issue; cultural and social norms of conduct) together established Andrew's capacities. These centred upon serial heterosexual dating within a competitive environment with his male 'mates', but marked also by anxieties and perceived psychological and physical inadequacies produced by insecurities concerning his stature and his health.

Analysis of transcripts in this series revealed further, unique sexualityassemblages. For 'Najib', a 20-year-old student, relations included women, his peer group, his self-image, physical attractiveness, his ethnicity, marriage, past sexual experiences and concerns with hygiene (clinical and moral) that produced a fastidiousness in his sexual conduct. He too frequented clubs with a group of mates, and described competitive efforts to 'pull' the 'best girl in the club'. Another student 'Neil' was in a steady relationship, and his sexuality-assemblage included not only his girlfriend, but also his family, male friends, past girlfriends, the university, music, the gym, his body shape, alcohol, pubs, and discourses on male and female sexuality.

These two sources of data thus revealed the broad range of material relations (animate and inanimate; physical, psychological, social and abstract) in young men's sexuality-assemblages: significant others (mates, girlfriends, parents, teachers); the physical spaces where they interact and socialise, social activities, cultures and backgrounds, and abstract concepts such as love, sexual fidelity or honesty. While this suggests the idiosyncratic, unstable and fluctuating composition of sexuality-assemblages, it also identifies relations and affects that occur more generally. From the teenage boys in the school dataset - who focused primarily upon the embodied pleasures that sexual arousal could provide - to the university students for whom a social life revolving around alcohol, clubs and pubs, and abstract ideas of love and fidelity often appeared in these sexuality-assemblages, there were recurrent threads that cut across individual sexuality-assemblages.

However, of more interest than simply listing the relations in these sexualityassemblages are the fluxes, stabilities and instabilities produced as the affect economies within them shift and reconfigure, disperse or re-form. The second phase of analysis focused upon these movements, and the micropolitics of assemblage intra-action they reveal. We sought out the territorialisations that produced relatively stable capacities in young men, the de-territorialisations that undermined these and established different sexual or other capabilities, the aggregations that grouped or unified aspects of young men and sexuality, and the singular affects that occasionally offered new capacities and possibilities for sexuality or subjectivity. 


\section{The micropolitics of young men and sexuality}

Data from both sources provide examples of territorialisation of capacities by physical/biological, psychological and sociocultural affectivities within the sexuality-assemblage. For the teenage boys, physical relations such as bodily maturation, height, voices that had 'broken' and facial hair territorialised childish bodies into adolescence and adulthood. These physical affects combined with competitive and hierarchical displays of machismo or intimidation within the peer group to further territorialise and effectively rank their bodies (and their girlfriends and even their cars) in terms of physical capacities.

For the older group, a similar territorialisation occurred, though produced from the differing affect economies assembled in university and workplace milieux. The physical affectivity associated with sexual desires and experiences was vividly described by 20 -year-old student Sonny.

When I crave sex, when I'm single I crave, like, sort of, hot passionate sex with someone I love. So when I have that it's very important. It's like... it's like dripfeeding you or something, it's just like pure, you know, it's just great... That's what I crave all the time, and if I've not got that then I can get disenchanted.

Several students including Andrew and Najib described the social assemblages they inhabited, comprising same-sex friendship groups, sporting activities, clubs and bars, alcohol, and social events where the main objective appeared to be for male students to 'pull' females, and vice versa. This micropolitics produced limited sexualities in these students and focused more upon competition between male peers than upon interaction with sexual partners: Scott expounded his efforts to be 'the person who's had a lot of sexual partners. You want to be the person who attracts the best looking girl in the bar', while Andrew entertained his 'mates' with salacious details of his sex life. Like the teenage boys, these bodies were ranked in terms of physical looks, to produce informal hierarchies of who might have sex with whom. Najib, whose good looks and attractiveness to women were reputedly widely acknowledged, described how he was territorialised by his peers into a situation where he effectively had to compete against himself.

They were all on my case, all of them, like 'Come on. We want to see you in action', and I was like 'No, no. I'm all right', you know. And they were all calling me 'chicken'. And I thought 'Oh no, here we go again'. You know, the ego thing, I was listening to part of them: 'Pick the best girl in the club, and I'm going to get with her.' So he picks out the - I mean this woman was amazing. You know, she was gorgeous. And all night I'm trying to pull this girl... you know, and I finally do.

This dating and mating assemblage territorialised respondents variously, from Andrew's serial cheating, to steady sexual relationships. Student Tim reflected 
back on a heterosexual relationship a year earlier that had territorialised both his sexuality and other areas of his life.

I spent most of my second year in university in one which I was always ... not really wanting to be in a relationship. Even though I was kind of wanting to be with this girl... And often I'd not want her to come out, but... she would always come out, and this would, it would really annoy me in a way, because you can't act in the same way if, if you're girlfriend's there or... or even, even with your mates you can't have the same ah.... chats and that.

The micropolitical significance of these territorialisations is further revealed by exploring the aggregating and non-aggregating (singular) effects they had on the young men in the two studies. Aggregative territorialisations drew both the teenage boys and the older group into narrow sexuality-assemblages. For example, the school-excluded teen boys were aggregated by the physical and social affects into an assemblage that valorised heterosexuality, homophobia and misogyny that was reflected in the 'banter' and horseplay witnessed in both the SRE classes and during the study focus groups. Physical maturation, actual or purported familiarity with heterosexual activity, competitive homophobic posturing and (hetero)sexualised banter sustained them within this assemblage, aggregating their sexuality into what some scholars have described as 'compulsory heterosexuality' and 'hegemonic masculinity' (Holland et al., 1998: 149; Mac an Ghaill, 1994: 96; Rich, 1980).

Similarly, the physical and social territorialisations in the older group were often powerfully aggregative, and the data offered examples of aggregation into a specific sexual orientation, an attraction to a specific physical body-type or ethnicity, or into close monogamous relationships. Paul, a student and keen sportsman who acknowledged he played rugby for reasons of body-appearance and to 'keep his girlfriend happy', described how physical, psychological and emotional needs were aggregated within a monogamous heterosexual relationship.

I think having a girlfriend outweighs, um, not having a girlfriend. You know, my mates are always desperate for it, and not getting any, and... and aside from the physical needs, I find that there, there's the emotional needs as well. And I, I think I'd be quite lonely if I ... You know, I've come to spend, like, any night I'm not busy I'm with my girlfriend. So I'm never on my own. Whereas if all of a sudden I was on my own I think I would get lonely, because I don't really like my own company that much.

Lester, an unemployed 18-year-old, expressed the pressures to find a girlfriend he had felt, from both his peers and his expectations for his life. The transitions these sexual encounters represented territorialised him as both adult and man.

I suppose it is quite an important marker your first girlfriend, or your first pull, or the first time you get laid. I suppose it is quite important as, like, a yeah 'Now I 
am ... more than I was yesterday', just because of that. It's kind of a rite of passage, maybe.

Further aggregative territorialisations of sexuality within this group derived from specific contexts, for example those associated with religious, moral or cultural backgrounds. These relations aggregated them into culturally-defined sexual codes: Stephen, a devout Christian, described sex before marriage as 'real rubbish', while cultural notions of physical and moral hygiene aggregated Najib within informal but prescriptive rules governing with whom he had sex.

Not all sexual territorialisations were aggregative, however: singular affects deriving from sexual encounters produced unique capacities in particular bodies, including emotions, personal perspectives on sexuality and opportunities for nurturing others. Ross, a 19-year-old student, found new capacities for sexual intimacy from a relationship:

I'm always looking for, um, you know, someone who I, sort of, could completely fall for ... and spend a lot of time with... Ah, it's nice to just have someone there. You know, I mean... someone who's, sort of, not going to judge you and, sort of, who knows you really well. And who, ah, sort of, accepts you for who you are I suppose... I sort of find that if you're really head over heels with someone and you're sleeping with them, there's this, sort of, like a really, really intimate feeling.

Some of these singular affects were not only non-aggregative, but produced deterritorialisations, opening up new capacities and possibilities for action and interaction. As Paechter (2006: 122) has argued, school is a place where children's bodies (including or perhaps especially their sexualities) are sidelined or even erased as part of the disciplinary regime. Consequently, SRE classes are unusual: rather than erasing bodies, sexual desire and arousal become the topic for education (Alldred and David, 2007: 96). Our data suggested that in these situations, sexual bodies were also a potential source of resistance, whereby educational agendas might be substituted by displays of pubescent male sexuality, banter, sexist and homophobic jokes and horseplay. While this behaviour can be seen as a territorialisation into a narrow 'hegemonic' masculinity, the physiology of male sexual desire and heterosexual experience or prowess also offered a de-territorialising line of flight for the boys excluded from school, away from their unsuccessful educational identities into alternative 'adult' sexual identities, as one boy suggested during a focus group interview:

Interviewer: Would you rather do sex education with the girls or [just with] the boys?

Boy 2: The girls.

Interviewer: Is that just so you can flirt with them?

Boy 2: No, not really, [laughing] you just sit next to them until you get a stiff on! 
The data from the older respondents also suggested how affective flows could produce de-territorialisations. Some were minimal or negative, arguably producing re-territorialisations: Muslim student Ghalib found female company constraining and 'unnatural', but actively sought it out as a means to avoid being aggregated into male companionship, which he feared might lead 'to becoming gay or something'. Marco (like some other students in the sample) had actively resisted territorialisation into a steady heterosexual relationship, which he worried might constrain his future opportunities.

I don't want to get into a relationship at the moment. I'm seeing a girl which [sic] I love dearly, but I feel it might get too involved, and I do not want that at the moment. I feel I, I feel I need to run away from it for, for that reason... .

However, another student, Neil hesitantly revealed how a sexual relationship had produced new capacities in him that mitigated threats and risks in his daily life.

You can talk to your girlfriend unlike the way you can talk to pretty much any other person. Like, there's just ... there's a bond that forms ... like you can literally just say what's, whatever is on your mind. And, ah ... and just, I don't know, that feeling of trust as well, that someone actually is thinking about you all the time... and you're thinking about them ... It's like, it's like a, it's like a kind of bubble amongst the ah ... I don't know, because the world's pretty ... I don't want to say dark, because that's a bit unfair. But it's not... it's kind of like... scary sometimes. Like when you, when you think about how much shit is going on on the earth, and how many wars and all that. And I think loving... one other person is a, it's a good way of just, kind of, finding a meaning. You know, it feels like it's not all for nothing, and that there is a point.

In summary, these data demonstrate movements of territorialisation and de-territorialisation, aggregation and dis-aggregation in the sexuality-assemblages surrounding boys and young men, reflecting continual shifts in the micropolitical flows of power and resistance between and within bodies, and the instability of sexuality for young men. Territorialisations and aggregation that reproduce 'hegemonic masculinity' are countered by flows that fracture these dominant forms, and open up new possibilities: we consider the significance of this for understanding young men's sexuality in the following discussion.

\section{Discussion}

Sexuality is an area of human existence that refuses reduction to either biology or culture, with the physicality of sexual desire and arousal intricately linked to genetics, psychology, health, interactions and culture. Our materialist analysis of young men's sexuality has documented some of the complex mix of animate and inanimate relations that assemble around sexual behaviours, regimes and identities, and we conclude with some reflections on our findings. These suggest that a sexuality- 
assemblage is not a stable entity, but one that is constantly in flux, awash with flows of affect that aggregate and dis-aggregate relations, that territorialise bodies into this or that assemblage but may then loose them on a sexual line of flight. Data from two disparate sources suggest that for young men, bodies and sexualities are territorialised by myriad affects in the sexuality-assemblage deriving variously from physiology, from social interactions with peers or sexual partners, with institutions such as schools or clubs, and by things such as condoms and alcohol. But from another perspective, even the territorialising and aggregating heteronormative banter and disruption of SRE classes, or the ritualised competitiveness of male students 'on the pull', can be a de-territorialisation or a line of flight.

While territorialisation and de-territorialisation are inevitable features of social life, the distinction between aggregating and singular affects is of more significance for our understanding of sexuality. Sexually, a body may be highly aggregated: by psychological, social and cultural inscription into a hetero- or homosexual orientation; into a structured manifestation, be that monogamy, celibacy or promiscuity; by cultural codes surrounding sexual conduct (Foucault, 1981: 103-105); or by scientific knowledge. On the other hand, expressions of sexuality can harness powerful singular affects deriving from physical or emotional intimacy, or from embodied and psychological pleasures, that may stand not only in place of aggregation but even disrupt an aggregated affect economy, radically de-territorialising a body into a sexual line of flight (cf. Renold and Ringrose, 2008: 316).

Such analysis offers a more optimistic perspective on how sexuality has been considered in terms of power and resistance than in either Foucault's work (which sees sexual pleasure as progressively encircled by a scientia sexualis), or in perspectives that emphasise hegemonic forms of masculinity characterised by homophobia, misogyny and compulsory heterosexuality (Mac an Ghaill, 1994: 96). In our materialist analysis, 'hegemonic masculinity' is not to be treated as an 'explanation' of young men's heterosexual identities, but a consistent and frequent emergent property, to be explained at the level of actions, interactions and events. It is a social form reproduced by a complex mix of affects deriving from biology and culture, including the affects in the school environment, the cultures of laddism, popular and online media (Bale, 2011) and in the stereotyped patternings of sexual encounters.

But these affect economies and micropolitics also contain within them singular affects which have the capacity to break bodies and subjectivities free from these aggregations. Though sexuality is typically highly constrained, there is always the possibility for it to become other. This poses challenges for how we consider sex and sexuality. As Alldred and David (2007: 96) commented:

The sexual body is nowhere educated. Learning might involve naming body parts and sexual health risks, but the body and its pleasures are clearly 'out of sight' - the superior mind is master to the body with its mistrusted licentious ways.

This absence reflects a deeper ambivalence to sexuality in contemporary culture that silences all but its normative and pathologised forms (Alldred and David, 
2007: 97). If sexuality and sexual pleasure are to become the subjects of education, or more broadly, to become central parts of human existence neither continually suppressed nor mired in innuendo, humour or phobias, then they must do so in all their transgressive rawness, recognising the possibilities for sexuality, for embodied and interpersonal pleasures, and for sexual lines of flight that do not aggregate bodies and individuals into narrow and constraining manifestations.

Our findings reveal that for many young men, the sexuality-assemblage is highly conventional and narrowly defined. This impoverished sexuality is everywhere aggregated and territorialised: by cultural norms of sexual behaviour and expectations imbued with patriarchal and heteronormative biases; by daily interactions between boys and girls, men and women (be this a misogynistic teen peer group or a ritualised dating game); by the genitalisation of sexuality; and by broader social and economic processes. These also often contribute to narrow formations of masculinity, be they 'hegemonic', 'marginalised' or 'subordinated' (Beasley, 2014: 5). But beyond this depleted sexuality always lurks the possibility for new desires, pleasures and capacities, ruptures and resistances that shift bodies way beyond the kinds of conceptions of sexes, genders and sexualities that inform many of these territorialised and aggregated masculinities. The value of this materialist approach rests in revealing the sexuality-assemblage not as an attribute of an individual body or human subject, but as a material, micropolitical field within which young male bodies and subjectivities are assembled, from which normative forms of masculinity and sexuality are produced and reproduced, but within which resistance and becoming-other are always possible.

\section{Notes}

1. Some authors in the social study of sexuality draw on both interactionist and poststructuralist traditions.

2. Data gathered by Roger deVisser and Jonathon Smith as part of the ESRC-funded Young Men, Masculinities and Health study (2003-2004); UK Data Archive, University of Essex (UKDA 5371). This was a self-selected sample recruited by advertisements in universities, employment offices and a local newspaper, but subsequently stratified to provide diversity in social class and ethnicity.

\section{References}

Alldred P and David M (2007) Get Real about Sex. Maidenhead: Open University Press.

Bale C (2011) Raunch or romance? Framing and interpreting the relationship between sexualized culture and young people's sexual health. Sex Education 11(3): 303-313.

Barad K (1996) Meeting the universe halfway: Realism and social constructivism without contradiction. In: Nelson LH and Nelson J (eds) Feminism, Science and the Philosophy of Science. Dordrecht: Kluwer, pp. 161-194.

Barker M (2005) This is my partner, and this is my...partner's partner: Constructing a polyamorous identity in a monogamous world. Journal of Constructivist Psychology 18(1): 75-88. 
Beasley C (2014) Caution! Hazards ahead: Considering the potential gap between feminist thinking and men/masculinities theory and practice. Journal of Sociology. Epub ahead of print 17 October 2014. Doi:10.1177/1440783314553317.

Beckman F (2011) 'Introduction: what is sex? An introduction to the sexual philosophy of Gilles Deleuze'. In: Beckman F (ed.) Deleuze and Sex. Edinburgh: Edinburgh University Press, pp. 1-29.

Braidotti R (2000) Teratologies. In: Buchanan I and Colebrook C (eds) Deleuze and Feminist Theory. Edinburgh: Edinburgh University Press, pp. 156-172.

Braidotti R (2006) Transpositions. Cambridge: Polity.

Braidotti R (2011) Nomadic Theory. New York: Columbia University Press.

Braidotti R (2013) The Posthuman. Cambridge: Polity.

Bridges T and Pascoe CJ (2014) Hybrid masculinities: New directions in the sociology of men and masculinities. Sociology Compass 8(3): 246-258.

Clough PT (2004) Future matters: Technoscience, global politics, and cultural criticism. Social Text 22(3): 1-23.

Connell RW (1987) Gender and Power: Society, the Person, and Sexual Politics. London: Allen \& Unwin.

Connell RW and Messerschmidt JW (2005) Hegemonic masculinity: Rethinking the concept. Gender \& Society 19(6): 829-859.

Coole DH and Frost S (2010) Introducing the new materialisms. In: Coole DH and Frost S (eds) New Materialisms: Ontology, Agency, and Politics. Durham, NC: Duke University Press, pp. 1-43.

DeLanda M (2006) A New Philosophy of Society. London: Continuum.

Deleuze G (1988) Spinoza. Practical Philosophy. San Francisco CA: City Lights.

Deleuze G and Guattari F (1984) Anti-Oedipus: Capitalism and Schizophrenia. London: Athlone.

Deleuze G and Guattari F (1988) A Thousand Plateaus. London: Athlone.

Epstein D (1998) Real boys don't work: Underachievement, masculinity and the harassment of 'sissies'. In: Epstein D, Elwood J, Hey V, et al. (eds) Failing Boys? Issues in Gender and Achievement. Buckingham: Open University Press, pp. 96-108.

Foucault M (1981) The History of Sexuality Vol.1: The Will to Knowledge. Harmondsworth: Penguin.

Fox NJ and Alldred P (2013) The sexuality-assemblage: Desire, affect, anti-humanism. Sociological Review 61(6): 769-789.

Fox NJ and Alldred P (2014) New materialist social inquiry: Designs, methods and the research-assemblage. International Journal of Social Research Methodology. Epub ahead of print 6 June 2014. DOI: 10.1080/13645579.2014.921458.

Frosh S, Phoenix A and Pattman R (2002) Young Masculinities. Basingstoke: Palgrave.

Gagnon JM and Simon W (1973) Sexual Conduct. Chicago, IL: Aldine.

Holland J, Ramazanoglu C, et al. (1998) The Male in the Head. London: Tuffnell Press.

Holmes D, O'Byrne P and Murray SJ (2010) Faceless sex: Glory holes and sexual assemblages. Nursing Philosophy: An International Journal for Healthcare Professionals 11(4): 250-259.

Kimmel MS (2008) Guyland: The Perilous World Where Boys Become Men. New York: Harper.

Lambevski SA (2005) Bodies, schizo vibes and hallucinatory desires - sexualities in movement. Sexualities 8(5): 570-586.

Lees S (1993) Sugar and Spice. Sexuality and Adolescent Girls. Harmondsworth: Penguin. 
Linstead S and Pullen A (2006) Gender as multiplicity: Desire, displacement, difference and dispersion. Human Relations 59(9): 1287-1310.

Mac an Ghaill M (1994) The Making of Men. Buckingham: Open University Press.

Masny D and Waterhouse M (2011) Mapping territories and creating nomadic pathways with multiple literacies theory. Journal of Curriculum Theorizing 27(3): 287-307.

Moscheta MS, McNamee S and Santos MA (2013) Sex trade among men: Negotiating sex, bodies and identity categories. Psicologia \& Sociedade 25: 44-53.

Mulcahy M (2012) Affective assemblages: Body matters in the pedagogic practices of contemporary school classrooms. Pedagogy, Culture \& Society 20(1): 9-27.

Nayak A and Kehily MJ (2006) Gender undone: Subversion, regulation and embodiment in the work of Judith Butler. British Journal of Sociology of Education 27(4): 459-472.

Paechter C (2006) Reconceptualizing the gendered body: Learning and constructing masculinities and femininities in school. Gender and Education 18(2): 121-135.

Pascoe CJ (2005) 'Dude, you're a fag': Adolescent masculinity and the fag discourse. Sexualities 8(3): 329-346.

Probyn E (1995) Queer belongings: The politics of departure. In: Grosz E and Probyn E (eds) Sexy Bodies. London: Routledge, pp. 1-18.

Renold E and Ivinson G (2014) Horse-girl assemblages: Towards a post-human cartography of girls' desire in an ex-mining valley's community. Discourse: Studies in the Cultural Politics of Education 35(3): 361-376.

Renold E and Ringrose J (2008) Regulation and rupture: Mapping tween and teenage girls' resistance to the heterosexual matrix. Feminist Theory 9(3): 313-338.

Renold E and Ringrose J (2011) Schizoid subjectivities? Re-theorizing teen girls' sexual cultures in an era of 'sexualization'. Journal of Sociology 47(4): 389-409.

Rich A (1980) Compulsory heterosexuality and lesbian existence. SIGNS: Journal of Women in Culture and Society 5(4): 631-660.

Ringrose J (2011) Beyond discourse? Using Deleuze and Guattari's schizoanalysis to explore affective assemblages, heterosexually striated space, and lines of flight online and at school. Educational Philosophy and Theory 43(6): 598-618.

Schalet AT (2000) Raging hormones, regulated love: Adolescent sexuality and the constitution of the modern individual in the United States and the Netherlands. Body \& Society 6(1): 75-105.

Schalet AT (2011) Not Under my Roof. Parents, Teens and the Culture of Sex. Chiacago, IL: University of Chicago Press.

Taylor CA and Ivinson G (2013) Material feminisms: New directions for education. Gender and Education 25(6): 665-670.

van der Tuin I and Dolphijn R (2010) The transversality of new materialism. Women: A Cultural Review 21(2): 153-171.

Youdell D and Armstrong F (2011) A politics beyond subjects: The affective choreographies and smooth spaces of schooling. Emotion, Space and Society 4(3): 144-150.

Pam Alldred is Senior Lecturer and Director of the Centre for Youth Work Studies in the Division of Social Work, Brunel University.

Nick J Fox is Honorary Professor of Sociology at the University of Sheffield School of Health and Related Research. 